\title{
Developmental Changes in Rat Brain 5'- Deiodinase and Thyroid Hormones during the Fetal Period: The Effects of Fetal Hypothyroidism and Maternal Thyroid Hormones ${ }^{1}$
}

\author{
CARMEN RUIZ DE OÑA, MARIA JESUS OBREGÓN, FRANCISCO ESCOBAR DEL REY, AND \\ GABRIELLA MORREALE DE ESCOBAR \\ Unidad de Endocrinología Experimental, Instituto de Investigaciones Biomédicas, C.S.I.C. and Facultad \\ Autónoma de Medicina, Madrid, Spain
}

\begin{abstract}
We have studied the ontogenesis of $5^{\prime}$-deiodinase $\left(5^{\prime} D\right)$ activity in rat brain during fetal life, its capacity to respond to maternal or fetal hypothyroidism, and its regulation by maternal thyroid hormones. Type II $5^{\prime} \mathrm{D}\left(5^{\prime} \mathrm{D}-\mathrm{II}\right)$ activity increases 4-fold during the period studied (17 to 22 days of gestation), mainly between days 19 and 21 . Fetal brain T4 concentrations increase in parallel with fetal plasma T4, whereas fetal brain T3 concentrations increase 18 times (days 17-21), six times more than would have been expected from the small increase in fetal plasma T3 levels. Maternal thyroidectomy did not affect $5^{\prime} \mathrm{D}$-II activity or thyroid hormone concentrations in fetal brain (except brain T4 at 18 days of gestation). Fetal hypothyroidism, induced by giving a goitrogen (methimazole) to the mothers, depleted all fetal tissues studied, including the fetal thyroid, from thyroid hormones. By 19 days of gestation, the fetal brain was able to respond to hypothyroidism with a 3- to 5-fold increase in 5'D-II activity. Earlier onset of treatment with methimazole led to 2- to 3-fold increases in 5'D already at 17 and 18 days of gestation, showing that when fetal thyroid secretion starts the fetal brain $5^{\prime} \mathrm{D}-\mathrm{II}$ is able to respond to hypothyroidism. Replacement of methimazole-treated mothers with physiological doses of $\mathrm{T4}$, given by constant infusion, increased $\mathrm{T} 4$ and $\mathrm{T} 3$ concentrations in fetal brain, and inhibited fetal, as well as maternal, brain 5'D-II activity. But treatment of the mothers with T3 did not change T3 concentrations in the fetal brain, despite the increase in fetal plasma $\mathrm{T} 3$, and actually increased $5^{\prime} \mathrm{D}$-II in fetal brain. Maternal cerebral 5'D-II was not inhibited by T3 treatment. Inverse relationships were found between the $5^{\prime} \mathrm{D}$-II and thyroid hormone concentrations in the fetal brain. These correlations were not identical for fetuses from thyroidectomized and control mothers. In fetuses from thyroidectomized dams, brain $5^{\prime} \mathrm{D}$-II is more sensitive to a decrease in brain $\mathrm{T} 4$ than in the progeny of control
\end{abstract}

Received March 31, 1988; accepted July 6, 1988.

Correspondence and requests for reprints: Dr. Maria Jesus Obregón, Unidad de Endocrinologia Experimental, Instituto de Investigaciones Biomédicas, Facultad Autónoma de Medicina. Arzobispo Morcillo 4, 28029 Madrid, Spain.

Supported in part by grant from Comisión Asesora de Investigacion Científica y Tecnica (PR-84-0205) and from Plan Nacional para Prevención de Subnormalidad of Spain. C.R. is the recipient of a fellowship from Plan de Formacion de Personal Investigador del Gobierno Vasco.

A preliminary report was presented at the 16 th Annual Meeting of the European Thyroid Association, Laussane, and has appeared in Ann Endocrinol 1987;164:176 A(abstr). dams. The present results describe the developmental changes in rat cerebral $5^{\prime} \mathrm{D}$-II activity and its regulation by thyroid hormones. Although fetal plasma T3 is $10 \%$ of adult levels, T3 concentrations in fetal brain increase almost to adult levels, suggesting an important role of local $\mathrm{T} 3$ production from T4, and thus, of $5^{\prime} \mathrm{D}$-II in fetal brain. In addition, brain $5^{\prime} \mathrm{D}$-II responds to thyroid hormone deficiency and can be modulated by maternal thyroid hormones when the fetus is hypothyroid. (Pediatr Res 24: 588-594, 1988)

\section{Abbreviations}

\author{
$5^{\prime} \mathrm{D}, 5^{\prime}$-deiodinase \\ 5'D-II, type II-5' deiodinase \\ MMI, methimazol \\ PTU, propylthiouracil \\ C, control \\ T, Thyroidectomy, thyroidectomized \\ T4, thyroxine, tetraiodo-thyronine \\ T3, 3', 3, 5 -triiodo-thyronine \\ rT3, reverse $\mathrm{T3}$ \\ $3^{\prime}, 5^{\prime}, 3$, triiodo-thyronine \\ RIA, radioimmunoassay \\ DTT, dithiothreitol \\ BW, body weight \\ dg, days of gestation \\ $P$, protein \\ TSH, thyroid-stimulating hormone
}

Thyroid hormones are known to play an important role in brain maturation. Their absence during development leads to irreversible brain damage $(1-3)$. The defects resulting from thyroid hormone deficiency in the developing brain are well described both for congenital hypothyroidism and endemic cretinism (4-6), but the biochemical mechanisms involved are not yet fully defined $(7,8)$, nor the timing at which the developing brain is more sensitive to the absence of thyroid hormones. Nuclear receptors for T3 have been described in the adult and fetal brain (9-12) but the postreceptor events are also still poorly understood.

Most nuclear and intracellular T3 of the adult and neonatal brain is locally produced from $\mathrm{T} 4$, by $5^{\prime} \mathrm{D}(13-15)$. The deiodination process, different from the one described in liver and kidney, has been identified in its kinetics characteristics: low $\mathrm{Km}$ 
(2 $\mathrm{nM}$ ), with preference for $\mathrm{T} 4$ as substrate and insensitive to inhibition by PTU. Its physiologic regulation has extensively studied (16-19): it increases in hypothyroidism and is regulated by thyroid hormones $(20-22)$. Thyroid hormone concentrations in brain are maintained by several mechanisms, which include selective uptake and deiodinative processes $(23,24)$.

In previous studies $(25,26)$ we have reported that thyroid hormones are present in the fetal brain (days 20 and 21 of gestation), in greater amounts (about $50 \%$ of adult levels) than was previously thought, despite low plasma T3 levels. In contrast with other fetal tissues, maternal thyroidectomy had little effect on fetal brain T4 and T3 concentrations (25), suggesting that mechanisms for the maintainance of cerebral $\mathrm{T} 3$ homeostasis are already present at this stage of development.

The aims of the present work were to study: 1 ) the development of $5^{\prime} \mathrm{D}-\mathrm{II}$ in the fetal brain, 2) the possible contribution of this enzyme to the changes in fetal brain $\mathrm{T} 3$ concentrations, 3 ) the capacity of $5^{\prime} \mathrm{D}-\mathrm{II}$ to respond to fetal or maternal hypothyroidism, and 4) its possible modulation by maternal thyroid hormones when the fetus is hypothyroid.

\section{MATERIALS AND METHODS}

Experimental design. Female Wistar rats were used. They were fed, housed, and $\mathrm{T}$ as previously described (25). Two months after $\mathrm{T}$, or later, rats with undetectable plasma T4 were mated ( $\mathrm{T}$ dams) with normal males. Intact age-paired females were also mated (C dams). The day of appearance of the vaginal plug was considered as day 0 of fetal age (25).

Some of the $\mathrm{C}$ and $\mathrm{T}$ dams were given $0.02 \% \mathrm{MMI}$ as drinking water, starting at $14 \mathrm{dg}$ (CMMI or TMMI), except for a single experiment, when pregnant rats were given MMI from $12 \mathrm{dg}$. Some of the MMI-treated dams were implanted at $15 \mathrm{dg}$ with osmotic minipumps delivering T4 (1.8 $\mu \mathrm{g} \mathrm{T} 4 / 100 \mathrm{~g} \mathrm{BW} /$ day) or T3 $(0.45 \mu \mathrm{g} \mathrm{T} 3 / 100 \mathrm{~g} \mathrm{BW} /$ day $)$ at a constant rate, as detailed elsewhere (26).

C, CMMI, T and TMMI dams were killed, bled, and perfused as described (25), except that 6-propyl-2-thiouracil (PTU) was excluded from the perfusion media to avoid interference with the measurement of $5^{\prime} \mathrm{D}$. Fetuses were obtained at different ages between 17 and $22 \mathrm{dg}$. Fetuses from MMI-treated $\mathrm{C}$ or T dams infused with $\mathrm{T} 4$ or $\mathrm{T} 3$, were only studied at $21 \mathrm{dg}$.

Plasma, liver, and brain were obtained from the mothers. Fetuses were dissected out from the uterus, bled (from $18 \mathrm{dg}$ onward), separated from the placenta, placed on ice, and weighed. The brain, thyroid, as well as other fetal tissues were dissected out, weighed, and quickly frozen on dry ice. Brain samples were used for the determination of $5^{\prime} \mathrm{D}$ activity and thyroid hormone concentrations.

Synthesis of radioactive $r T 3$ or T4. High specific activity ${ }^{125} \mathrm{I}-$ rT3 or ${ }^{125}$ I-T4 were synthesized as previously described (27), using $3^{\prime}, 3-\mathrm{T} 2$ or $3^{\prime}, 3,5-\mathrm{T} 3$ as substrates, respectively, and used for the deiodinase assay. ${ }^{125} \mathrm{I}-\mathrm{T} 3$ and ${ }^{131} \mathrm{I}-\mathrm{T} 4$ were obtained with the same method and used as tracers for individual recovery calculations during the preparation of plasma or tissue samples for the determination of T3 and T4 by RIA $(25,26)$.

Tracers used for the deiodinase assay were purified by descending chromatography (28), eluted with methanol- $\mathrm{NH}_{4} \mathrm{OH}(9: 1)$, evaporated to dryness, and kept in ethanol.

Determination of 5'D activity. Iodothyronine 5'D activity was assayed in fetal brain homogenates as previously described (17), measuring the release of ${ }^{125} \mathrm{I}^{-}$from ${ }^{125} \mathrm{I}-\mathrm{T} 4$ or ${ }^{125} \mathrm{I}-\mathrm{rT} 3(100,000$ $\mathrm{cpm} / \mathrm{vial}$ ) during $1 \mathrm{~h}$, in the presence of $2 \mathrm{nM} \mathrm{T} 4$ or rT3, respectively, $20 \mathrm{mM}$ DTT and in the presence $\left(5^{\prime} \mathrm{D}\right.$-II) or absence (5'D-total) of $1 \mathrm{mM}$ PTU. When using T4 as substrate, $1 \mu \mathrm{M}$ $\mathrm{T} 3$ was included in the reaction media, to prevent inner ring deiodination $(5 \mathrm{D})$. The lodide was separated by ion-exchange chromatography on Dowex-50W-X2 columns equilibrated in $10 \%$ acetic acid (29). The protein content was determined using the method of Lowry et al. (30). The amount of protein used was $100-150 \mu \mathrm{g} \mathrm{P} /$ vial. Results are expressed as fmols lodide/h/ mg P.

Production of lodide was linear from 50 to $250 \mu \mathrm{g}$ of protein/ vial, in control and hypothyroid fetal brain, and up to $2 \mathrm{~h}$ of incubation at $37^{\circ} \mathrm{C}$. Occasionally, the amounts of ${ }^{125}$ lodide and $3^{\prime}, 3 \mathrm{~T}_{2}$ (or $\mathrm{T} 3$, when using $\mathrm{T} 4$ as substrate) produced during the incubation were checked by descending chromatography using the system described by Bellabarba et al. (28), to assess the production of equal amounts of iodide and metabolites.

All the values shown are the mean of at least five to six determinations using duplicates, and the fetal samples of a given group were obtained from at least two different dams. Most experiments were repeated more than once to check for reproducibility.

Several series of homogenates were assayed using T4 as well as rT3 as substrates. As already described (see "Results" and "Discussion"), when using $2 \mathrm{nM}$ rT3, 5'D-II constituted a lower percentage of total $5^{\prime} \mathrm{D}$, than when using T4. Differences observed in $5^{\prime} \mathrm{D}$-II (as \% of total $5^{\prime} \mathrm{D}$ ) when using rT3 or T4 were minimal in MMI-treated fetuses (5-10\%), and somewhat higher in C fetuses (20-30\% higher when using T4 as substrate).

Other determinations. Thyroid hormone concentrations were determined by RIA, as previously described (31). In brief, plasma and brain samples were extracted with methanol and purified using chloroform-methanol extraction, and back-extraction into an aqueous phase, followed by purification of this phase on BIORAD AG $1 \times 2$ resin columns, as described in detail elsewhere $(25,26)$. Thyroid hormone concentrations were determined in the purified extracts.

Statistical analysis. Mean values \pm SEM are given. These values and the significance of difference between group means (Student's $t$ test) were calculated as described by Snedecor and Cochran (32). For comparisons of mean values in experiments involving several experimental groups, one- or two-way analysis of variance was used after square root or logarithmic transformations to ensure homogeneity of variances (Bartlett's test), if not found with the raw data. When the variance ratio indicated the presence of statistically significant differences between mean values, these were identified by the protected least significant difference test (32).

\section{RESULTS}

Ontogenesis of $5^{\prime} D$ activity in fetal brain. The development of 5'D activity was examined in fetal brain homogenates, using samples from 17 to $22 \mathrm{dg}$. This comprises a developmental period starting before onset of fetal thyroid secretion, at 17.5-18 dg, up to a few hours before birth.

In some assays, both rT3 and T4 were used as substrates of the deiodinative reaction. As already described $(17,24)$, the \% of inhibition by PTU is higher using rT3 than T4, but the conclusions are the same using either substrate. Due to very low activities found on days 17 and 18 when using rT3, T4 was used as the preferred substrate for exploring $5^{\prime} \mathrm{D}$-II activities.

When T4 was used as substrate, $5^{\prime} \mathrm{D}$-II activities were around $80 \%$ of total $5^{\prime} \mathrm{D}$ activities, indicating that under our conditions most T4 $5^{\prime}-\mathrm{D}$ activity is PTU insensitive (type II). Figure 1 (upper panel) shows a 6 -fold increase in brain T4 5'D-II during the developmental period studied, the main increase taking place between 19 and $21 \mathrm{dg}$. This means that, in 2 days, the potential capacity of fetal brain to produce T3 increases three times. As will be explained below (Fig. 2), conclusions are similar using rT3 as substrate.

The changes in thyroid hormone concentrations occurring in the fetal brain and plasma are illustrated in the lower and middle panels of Figure 1 (note different scales for plasma and brain T4 and T3). As may be seen, brain and plasma T4 concentrations increased markedly between 18 and $21 \mathrm{dg}$, about 9- and 8-fold, respectively, in only 3 days. T4 concentrations in fetal brain doubled each day of gestation (18-21 dg). Brain T3 concentra- 

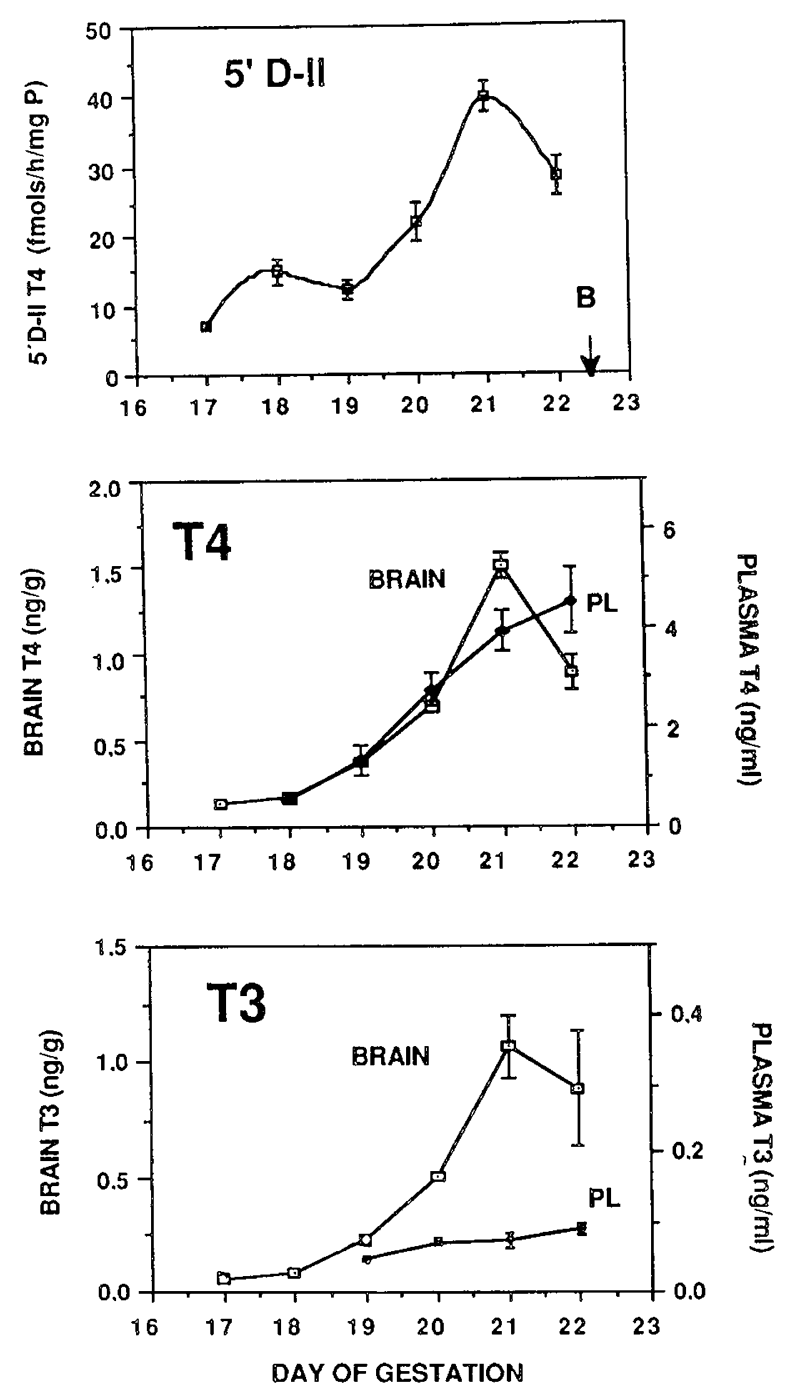

Fig. 1. The upper panel shows T4 5'D-II activity in fetal brain (17$22 \mathrm{dg}$ ). A total of $2 \mathrm{nM} \mathrm{T} 4$ was used as substrate. Results are expressed in fmols of lodide/ $/ \mathrm{h} / \mathrm{mg} P$ (six fetal samples/group, with fetuses from two different dams in each group). Increases were statistically significant $(p<0.05)$ between days 17 and 18 and from 19 to $21 \mathrm{dg}$, with a decrease between 21 and $22 \mathrm{dg}$. $B$, indicates birth. The middle panel shows T4 concentrations in brain and plasma of fetuses from $C$ mothers during the same period as specified above. No fetal plasma was available on day 17. Results are expressed as $\mathrm{ng} \mathrm{T} 4 / \mathrm{g}$ or $\mathrm{ml}$. Increases are statistically significant from 18 to $21 \mathrm{dg}$, both for brain and plasma, with a decrease between 21 and $22 \mathrm{dg}$ for brain T4. The lower panel shows T3 concentrations in brain and plasma of fetuses from $\mathrm{C}$ mothers. No plasma values were obtained at 17 and $18 \mathrm{dg}$. Results are expressed as ng T3/g or $\mathrm{ml}$. Increases are statistically significant from day 18 for brain $\mathrm{T} 3$, and only between 19 and $22 \mathrm{dg}$ for plasma T3.

tions increased even more: 18-fold increase from days 17 to 21 , and about 12 -fold between days 18 to 21 , but there was only a relatively small increase (2-fold) in the plasma $T 3$ levels during the same period.

Effects of maternal thyroidectomy on ontogenesis of $5^{\prime} D$. Fetal brain $\mathrm{T} 4$ and $\mathrm{T} 3$ concentrations are shown in Table 1 , for fetuses from $\mathrm{T}$ and $\mathrm{C}$ dams. They were the same for both groups, except for lower T4 levels at $18 \mathrm{dg}$, and lower T3 levels at $21 \mathrm{dg}$ in the brain of fetuses from $\mathrm{T}$ dams as compared with those from $\mathrm{C}$ dams. Determinations in fetal brains from $T$ dams at $17 \mathrm{dg}$ were not performed because of insufficient amount of tissue.

Maternal $\mathrm{T}$ affected the development of the fetuses as previously reported (25). It decreased the number of fetuses per dam

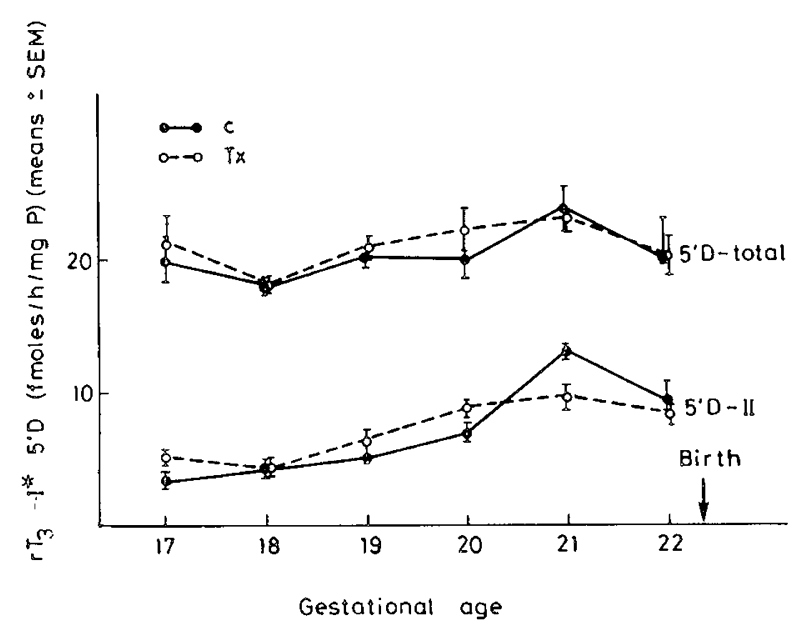

Fig. 2. Total and 5'D-II activity in fetal brain during gestation (days 17 to 22). Fetal brain from $\mathrm{C}$ and $\mathrm{T}$ mothers were used for comparison (closed and open circles, respectively). A total of $2 \mathrm{nM}$ rT3 was used as substrate. No statistically significant difference was found between fetal brain from $\mathrm{C}$ and $\mathrm{T}$ dams, except in $5^{\prime} \mathrm{D}-\mathrm{II}$ activities at $21 \mathrm{dg}$.

Table 1. Thyroid hormone concentrations in fetal brain in fetuses from $C$ and $T$ dams (mean $\pm S E M$ )

\begin{tabular}{|c|c|c|c|c|}
\hline \multirow{2}{*}{$\begin{array}{c}\text { Day of } \\
\text { gestation }\end{array}$} & \multicolumn{2}{|c|}{$\mathrm{T} 4(\mathrm{pg} / \mathrm{g})$} & \multicolumn{2}{|c|}{$\mathrm{T} 3(\mathrm{pg} / \mathrm{g})$} \\
\hline & $\mathrm{C}$ dams & $\mathrm{T}$ dams & $\mathrm{C}$ dams & $\mathrm{T}$ dams \\
\hline 17 & $124 \pm 20$ & & $60 \pm 14$ & \\
\hline 18 & $170 \pm 25$ & $94 \pm 21^{*}$ & $85 \pm 4$ & $77 \pm 7$ \\
\hline 19 & $364 \pm 19$ & $407 \pm 135$ & $231 \pm 6$ & $206 \pm 10$ \\
\hline 20 & $688 \pm 20$ & $690 \pm 10$ & $505 \pm 15$ & $560 \pm 10$ \\
\hline 21 & $1503 \pm 75$ & $1541 \pm 61$ & $1071 \pm 134$ & $813 \pm 45^{*}$ \\
\hline 22 & $880 \pm 100$ & $1232 \pm 273$ & $886 \pm 251$ & $821 \pm 119$ \\
\hline
\end{tabular}

from $11 \pm 0.6$ for $\mathrm{C}$ dams to $6.6 \pm 0.2$ for $\mathrm{T}$ dams $(p<0.005)$. The BW and organ weights of fetuses from $\mathrm{T}$ mothers were lower, although in the case of the brain, the relative weight increased (25).

Figure 2 shows the developmental changes in total and type II $5^{\prime} \mathrm{D}$ in the brain of 17- to 22-day-old fetuses from $\mathrm{C}$ and $\mathrm{T}$ mothers (using rT3 as substrate). Total $5^{\prime} \mathrm{D}$ did not change during the period studied. On the contrary, and in agreement with the data shown in Figure 1 (using T4 as substrate), 5' D-II increased steadily from $17 \mathrm{dg}$, reaching peak values at $21 \mathrm{dg}$, with an overall 4 -fold increase in the $\mathrm{C}$ group. The increase was statistically significant from day 19 onward in fetuses from $\mathrm{C}$ dams, and from day 20 in those from $T$ dams. The relative proportion of $5^{\prime} \mathrm{D}-\mathrm{II}$ over the total $5^{\prime}-\mathrm{D}$ activity also increased from $17 \%$ on day 17 , to $55 \%$ on day 21 .

No differences were found in total $5^{\prime} \mathrm{D}$ and $5^{\prime} \mathrm{D}-\mathrm{II}$ activities between fetal brain from $\mathrm{C}$ and $\mathrm{T}$ dams, although in some assays small, but statistically significant differences were found, as the ones seen in Figure 2 at $21 \mathrm{dg}$. In one experiment, using 17- and 18-day-old fetuses, we have found that fetal brain $5^{\prime} \mathrm{D}$-II was increased at $18 \mathrm{dg}[9.4 \pm 0.82(n=9)$ versus $3.9 \pm 0.56 \mathrm{fmol} / \mathrm{h} /$ $\mathrm{mg} \mathrm{P}(n=12)$ in fetuses from $\mathrm{T}$ and $\mathrm{C}$ mothers, respectively, $p$ $<0.001]$. T4 concentrations were lower in fetal brain at $18 \mathrm{dg}$ (Table 1).

Effect of fetal hypothyroidism on fetal brain $5^{\prime} \mathrm{D}$ activity. A combination of fetal and maternal hypothyroidism was induced by treating $\mathrm{C}$ or $\mathrm{T}$ dams with MMI from $14 \mathrm{dg}$. Treatment of the mother with MMI resulted in undetectable concentrations of $\mathrm{T} 4$ and $\mathrm{T} 3$ in the fetal thyroids, and markedly reduced their concentration in all fetal tissues $(26,33)$. In the fetal brain, T4 and T3 were also reduced ( $25-40 \%$ of $\mathrm{C}$ values): approximately $0.1 \mathrm{ng} / \mathrm{g}$ on $18-19 \mathrm{dg}$, and less than $0.4 \mathrm{ng} / \mathrm{g}$ on $20-21 \mathrm{dg}$. 
The effects of MMI treatment on fetal brain $5^{\prime} \mathrm{D}$ activity are shown in Figure 3. The bars represent total $5^{\prime} \mathrm{D}$ activity, whereas the hatched area represents the PTU-insensitive fraction, namely 5'D-II activity. No difference was observed in brain 5'D activity between fetuses from $\mathrm{C}$ or $\mathrm{T}$ mothers, either in the basal $5^{\prime} \mathrm{D}$ levels or in its response to MMI treatment. Treatment with MMI produced a 3 - to 5-fold increase in 5'D-II activity between 19 and $21 \mathrm{dg}$. MMI caused a small, but statistically significant, increase at $17 \mathrm{dg}$, both in fetuses from $\mathrm{C}$ and from $\mathrm{T}$ dams, but not at $18 \mathrm{dg}$.

This observation raised the question if $5^{\prime} \mathrm{D}-\mathrm{II}$ in fetal brain is able to respond to hypothyroidism at the early age of $17-18 \mathrm{dg}$, or if the lack of a clear response in $5^{\prime} \mathrm{D}$-II was due to the fact that the degree of hypothyroidism achieved was not severe enough to give a clear increase. To further clarify this point, pregnant rats were given MMI at $12 \mathrm{dg}$. This was done because we had observed (Ruiz de Oña C, Obregón MJ, unpublished data) that a period of 5 days of maternal treatment with MMI is needed to get a clear-cut increase in fetal brain $5^{\prime} \mathrm{D}$-II. Results are summarized in Figure 4. The enzymatic activity increased 2fold at $17 \mathrm{dg}$, and 3-fold at $18 \mathrm{dg}$.

Effect of placental transfer of thyroid hormones. We have previously shown that infusion of physiologic doses of T4 to pregnant rats on MMI, results in placental transport of the hormone and increased levels of T4 and T3 in most fetal tissues studied, as compared to those found in fetuses from dams on MMI alone (26). We wanted to know if $5^{\prime} \mathrm{D}-\mathrm{II}$ in fetal brain is sensitive to maternal transfer of $\mathrm{T} 4$ and we compared this transfer with that of T3. C and T dams, treated with MMI and infused with thyroid hormones were used.

The thyroidal status of the mothers were assessed by their plasma thyroid hormone and TSH concentrations. A complete study of the thyroidal state of the mothers is presented elsewhere (33). In brief, the doses of T4 and T3 infused into the MMItreated $\mathrm{C}$ and $\mathrm{T}$ dams were not supraphysiologic, as their plasma $\mathrm{T} 4, \mathrm{~T} 3$, and TSH were comparable to those found in C dams.

As already indicated, fetal T4 and T3 concentrations were markedly decreased by treatment of the dams with MMI. Maternal infusion of T4 increased T4 concentrations in fetal plasma and brain to $33-50 \%$ of C levels, as well as brain T3 (40-60\% of $\mathrm{C}$ levels), but did not increase fetal plasma T3 $(26,33)$. Maternal infusion with T3 increased fetal plasma T3 to C levels, as well as $\mathrm{T} 3$ concentrations in many fetal tissues (33), but not in the brain. It actually decreased fetal brain $\mathrm{T} 4$ concentrations.
Figure 5 shows the responses of 5 'D-II in the 21-day-old fetal brain from the eight groups of treated dams. The increase in enzymatic activity in response to MMI is partially reversed by treatment of the mother with $\mathrm{T} 4$, but not by maternal infusion with T3. In the T3-treated groups, 5'D-II activity in the fetal brains actually increased, in agreement with a decrease in brain T4. Similar responses were obtained using rT3 as substrate (see legend to Fig. 5). These results show that the hypothyroid fetal brain is able to respond to maternal thyroid hormone.

We have analyzed the relationship between brain thyroid hormone concentrations and 5'D-II activity in fetal brain, and results are presented in Figure 6 . We found that the inverse relationship between brain T3 and 5'D-II activity (lower panel) is identical in fetuses from $\mathrm{C}$ and $\mathrm{T}$ dams, but the one found between fetal brain T4 and 5'D-II (upper panel) is different for fetuses from $\mathrm{C}$ and $\mathrm{T}$ mothers. Brain $5^{\prime} \mathrm{D}$-II activity is more sensitive to small variations in brain $\mathrm{T} 4$ concentration in the fetuses from $\mathrm{T}$ mothers, and 5'D-II activity is already increased at $\mathrm{T} 4$ concentrations that are close to the normal range, e.g. 900 pg T4/g, whereas lower T4 concentrations have to be reached in the brain of fetuses from $\mathrm{C}$ dams to observe a $5^{\prime} \mathrm{D}-\mathrm{II}$ response of comparable intensity. These results suggest different set-points

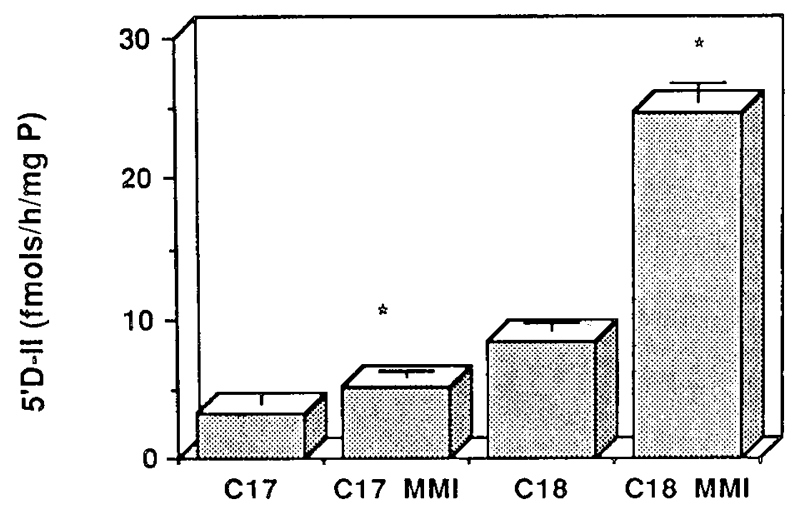

Fig. 4. Effect of MMI on 5'D-II activity from 17- and 18 days-old fetal brain. T4 was used as substrate. In this experiment $\mathrm{C}$ mothers were treated with MMI from day 12 of gestation. Asterisks represent statistically significant differences between $\mathrm{C}$ - and CMMI-treated fetuses at the level of $p<0.05$ or less. Results are the means obtained in two different experiments ( $n=12 /$ group).

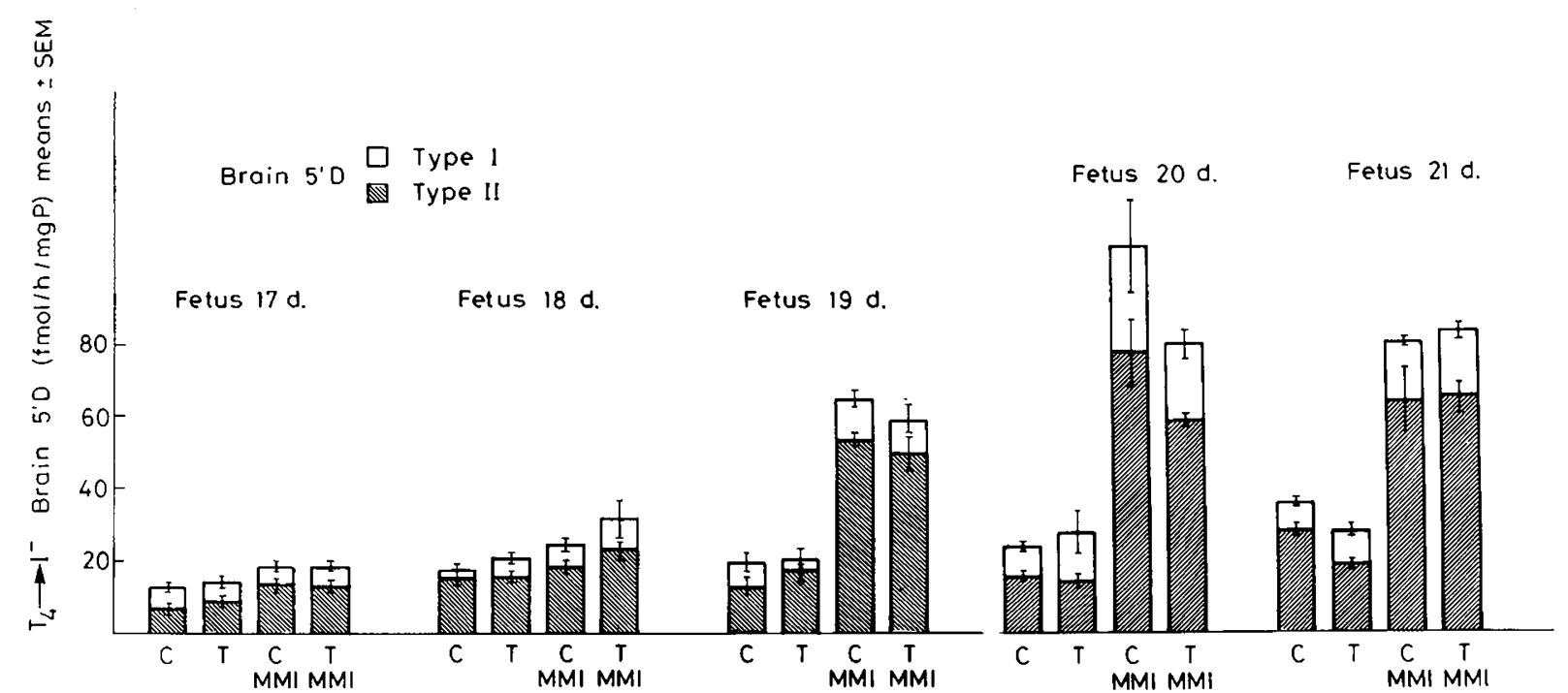

Fig. 3. Effects of MMI treatment on $\mathrm{T} 45^{\prime} \mathrm{D}-11$ activity in fetal brain from $\mathrm{C}$ and $\mathrm{T}$ mothers, from days 17 to 21 of gestation, using $\mathrm{T} 4$ as substrate. Total bars represent total 5' D activity, and the hatched bars represent 5'D-II activity. The increases in brain 5' D-II activity due to MMI treatment were always statistically significant for $\mathrm{C}$ and $\mathrm{T}$ groups, except in 18-day-old fetuses. No differences were found between $\mathrm{C}$ and $\mathrm{T}$ groups, either in basal or stimulated 5'D-II. 


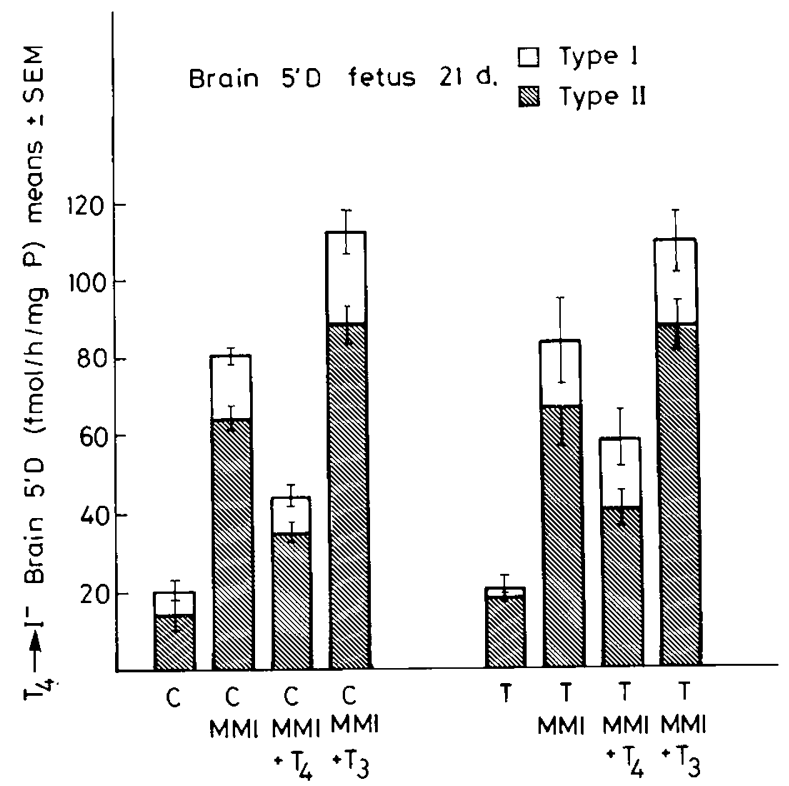

Fig. 5. Effect of maternal transfer of T4 or T3 on $5^{\prime} \mathrm{D}-\mathrm{II}$ activity in hypothyroid fetal brains. Brains from 21-day-old fetuses were used. Bars have the same meaning as in Figure 3. All differences between the $C$ (or $\mathrm{T}$ ) groups were statistically significant. No statistically significant difference was found between the $\mathrm{C}$ and $\mathrm{T}$ groups, e.g. CMMI versus TMMI. Results using $2 \mathrm{nM}$ rT3 as substrate were the same, although the inhibition by PTU was $10-20 \%$ higher.
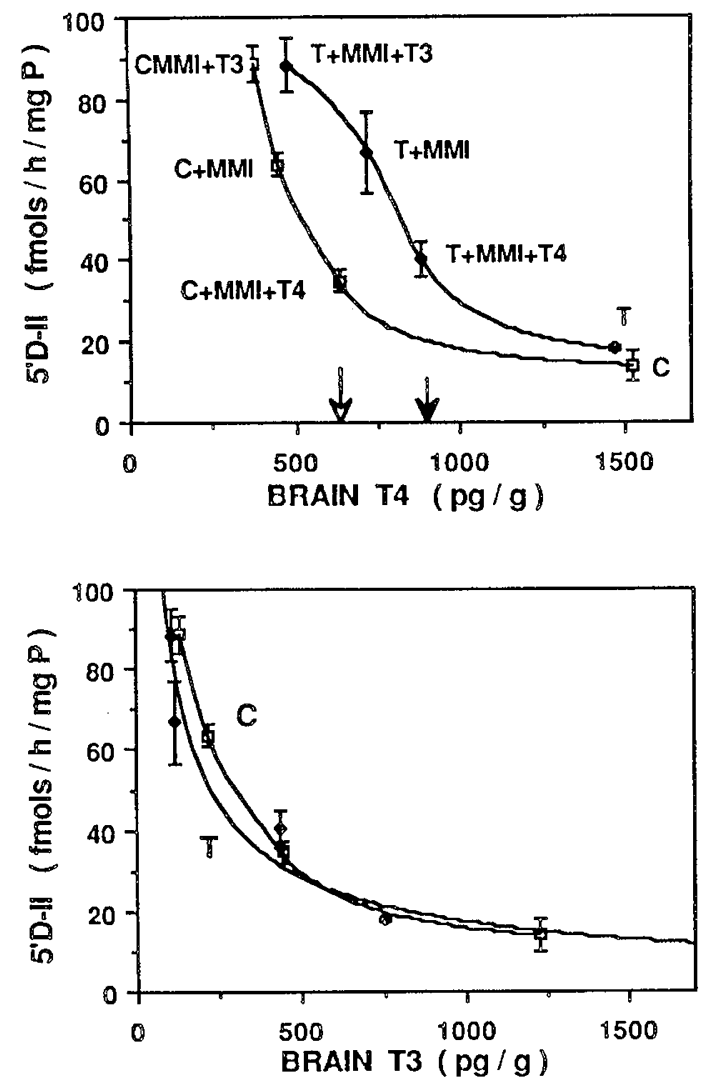

Fig. 6. Inverse relationships between thyroid hormone concentrations and $5^{\prime} \mathrm{D}-\mathrm{II}$ activity in fetal brain, from $\mathrm{C}$ and $\mathrm{T}$ dams. The arrows show brain $\mathrm{T} 4$ concentrations at which a significant increase in $5^{\prime} \mathrm{D}$-II activity is found in fetuses from $\mathrm{C}$ and $\mathrm{T}$ dams.
Table 2. T4 5'D-II in maternal brain from $C$ or $T$ pregnant rats, under MMI treatment, infused with T4 or T3 (mean \pm $S E M)^{*}$

\begin{tabular}{llc}
\hline $\begin{array}{c}\text { Treatment of } \\
\text { the dams }\end{array}$ & $n$ & 5'D-II \\
\hline C & 4 & $14.5 \pm 5.1$ \\
CMMI & 5 & $29.4 \pm 7.4 \dagger$ \\
CMMI + T4 & 3 & $3.9 \pm 0.9 \dagger \dagger$ \\
CMMI + T3 & 4 & $41.9 \pm 5.7 \dagger \S$ \\
T & & \\
TMMI & 5 & $96.5 \pm 4.3$ \\
TMMI + T4 & 3 & $64.9 \pm 1.6 \dagger$ \\
TMMI + T3 & 5 & $5.2 \pm 1.5 \dagger \ddagger$ \\
\hline
\end{tabular}

${ }^{*} \mathrm{C}$ and $\mathrm{T}$ dams were given $0.02 \% \mathrm{MMI}$ as drinking water, starting at $14 \mathrm{dg}$ (CMMI or TMMI). Some of the MMI-treated dams were implanted at $15 \mathrm{dg}$ with osmotic minipumps delivering $\mathrm{T} 4(1.8 \mu \mathrm{g} \mathrm{T} 4 / 100 \mathrm{~g} \mathrm{BW} /$ day) or T3 $(0.45 \mu \mathrm{g} \mathrm{T} 3 / 100 \mathrm{~g} \mathrm{BW} /$ day $)$.

$\dagger$ Difference with respect to data from the respective $\mathrm{C}$ or $\mathrm{T}$ group was significant, at the $5 \%$ level or less.

$\$$ Difference with respect to data from the respective CMMI or TMMI group was significant, at the $5 \%$ level or less.

$\S$ The same as $\dagger$ and $\ddagger$ but with respect to $\mathrm{MMI}+\mathrm{T} 4$ groups.

of regulation of $5^{\prime} \mathrm{D}$-II deiodinase activity in the brain of fetuses from $\mathrm{C}$ and $\mathrm{T}$ mothers.

$5^{\prime} \mathrm{D}$-II was also analyzed in cerebral cortex from $\mathrm{C}$ and $\mathrm{T}$ mothers treated with MMI, and infused with T4 or T3, and the activities found are presented in Table 2. Treatment with T4 inhibited maternal cerebral $5^{\prime} \mathrm{D}$-II, whereas treatment with T3 did not affect or suppress $5^{\prime} \mathrm{D}$-II activities in the maternal brain.

\section{DISCUSSION}

The present study tries to identify mechanisms that regulate the availability of thyroid hormones to the fetal brain during a period in which it is undergoing active development, with an especially rapid neuroblast multiplication. We have focused our attention on the $5^{\prime} \mathrm{D}$ mechanisms that contribute to $\mathrm{T} 3$ homeostasis in the fetal brain, as studies on T4 or T3 uptake by the brain during the fetal period are technically difficult, or might involve T4 metabolization during placental transfer.

Ontogenic development of $5^{\prime} \mathrm{D}$. We describe the ontogenic pattern of fetal brain $5^{\prime} \mathrm{D}$-II activity. A previous report using rT3 as substrate (34) found very low 5'D-II activity in 17-day-old fetal brain, with a 3-fold increase on the day of birth. Intermediate ages were not reported. Present results are in agreement with such findings.

The different profiles found for total 5'D activity when using T4 or rT3 as substrates confirms (17) that different potentialities are explored with each iodothyronine. They also show the specificity and preference of the enzyme for $\mathrm{T} 4$ as substrate, and that only the PTU-insensitive fraction of $5^{\prime} \mathrm{D}$ (type II) activity increases. Using rT3 as substrate, greater inhibition by PTU was observed than using $\mathrm{T} 4$, as described for adult brain $(17,24)$. We have some preliminary kinetic data (C. Ruiz de Oña, M. J. Obregon, F. E. del Ray, and G. Morreale de Escobar, unpublished results) comparing adult and fetal brain, using rT3 and T4 as substrates. For total $5^{\prime} \mathrm{D}, \mathrm{T} 4 \mathrm{~V}_{\max }$ and $\mathrm{T} 4 \mathrm{~V}_{\max } / \mathrm{Km}$ are higher in fetal than in adult brain, whereas when using rT3, the opposite occurs as both parameters are lower in fetal than in adult brain. When exploring $5^{\prime} \mathrm{D}-\mathrm{II}, \mathrm{V}_{\max } / \mathrm{Km}$ are similar when using either rT3 or T4 as substrate.

We have found a continuous increase in fetal brain $5^{\prime} \mathrm{D}-\mathrm{II}$ activity during the period of fetal development comprising onset of active fetal thyroid secretion. The increase was found using 
either rT3 or T4 as substrate. This increase suggests an increasing demand for local T3 production. This conclusion is supported by several findings reported here. The concentrations of T4 in the brain increase between 17 and $21 \mathrm{dg}$ at a somewhat greater rate than plasma $\mathrm{T} 4$ levels. This points to plasma $\mathrm{T} 4$ as the main source of cerebral T4. In contrast, cerebral T3 increases 6 times more than plasma T3, clearly indicating that plasma $\mathrm{T} 3$ is not the main source of cerebral T3. Moreover, infusion of T3 into MMI-treated dams increased fetal plasma T3, and the T3 concentration in many fetal tissues, but did not increase cerebral T3 (33). This also clearly supports the conclusion that $5^{\prime} \mathrm{D}$-II is essential for T3 homeostasis in the fetal brain, and that the fetal brain depends on local generation of $\mathrm{T} 3$, not on the uptake of plasma T3.

It is likely that during the period studied, the uptake of T4 by the brain might be increasing, and that this change also plays a role in determining the cerebral availability for $\mathrm{T} 4$, and ultimately, the generation of cerebral T3. As already indicated, brain T4 levels increased at a somewhat greater rate than plasma T4. But, considering the increasing activity of $5^{\prime} \mathrm{D}$-II, leading to increasing concentrations of $\mathrm{T} 3$ in the brain, it is possible that brain to plasma T4 ratios would lead to underestimation of the actual increase of T4 uptake by the brain. Actually, brain/plasma T4 ratios in the fetal brain $(0.24)$ are four times higher than the ratio found in the adult brain (0.06) (31). There is no evidence suggesting changes in the cerebral uptake of T3, which does not appear to contribute much to cerebral T3, at least as far as may be assessed from the data obtained at $21 \mathrm{dg}$. At present there is little information regarding a possible role of decreased cerebral degradation of $\mathrm{T} 3$, or decreased exit time, in the maintainance of fetal brain $\mathrm{T} 3$ concentrations.

The profile of 5D activity has been described to be high during the fetal and neonatal period, as compared with adult brain (3537). The $5 \mathrm{D}$ activity is inversely correlated with $5^{\prime} \mathrm{D}$ activities. Studies done using fetal brain cells in primary culture (38) show that inner ring deiodination is 25 times more active than the $5^{\prime} \mathrm{D}$ pathway. Studies done in glial cells in primary culture (39) show that $5 \mathrm{D}$ activity is found predominantly in astrocytes. How both pathways influence each other during fetal life remains a matter of discussion, but it is possible that rT3 production regulates $5^{\prime} \mathrm{D}$-II activities in a similar way as in the adult brain (22).

Responses to hypothyroidism. We have not found any major, or consistent, effect due to maternal thyroidectomy either in the 5'D-II activities (Figs. 2 and 3), nor in the developmental pattern of T4 or T3 concentrations in the fetal brain, except at $18 \mathrm{dg}$ (Table 1). This findings were expected (25), as no major differences in thyroid hormone concentrations in the brain were observed between fetuses from $\mathrm{C}$ and $\mathrm{T}$ dams $(20$ and $21 \mathrm{dg}$ ), despite the fact that $\mathrm{T} 4$ and $\mathrm{T} 3$ concentrations were lower in the thyroid and other tissues of fetuses from $\mathrm{T}$ dams. A role of deiodinative mechanisms to maintain cerebral $\mathrm{T} 3$ concentrations could not be excluded at that time.

Some of the present data suggest that maternal hypothyroidism does affect 5 'D-II in the fetal brain $(18 \mathrm{dg})$, before the fetal thyroid is able to compensate for the decrease in cerebral T4. Thus, although 5'D-II levels were still very low, this activity increased in 17- and 18-day old fetal brains, when obtained from $\mathrm{T}$, or MMI-treated C, dams. We believe this finding of interest, as it would indirectly show that the mechanisms to maintain cerebral T3 are becoming operative in parallel with the onset of fetal thyroid secretion.

When fetal thyroid hormone deficiency is induced by the administration of MMI to the mother, clear-cut responses of 5'D-II are apparent. Present results extend to fetal development the observation that neonatal hypothyroidism results in clear increases in brain $\mathrm{T} 45^{\prime} \mathrm{D}$ activities from the first day of extrauterine life (19). Brain T4 and T3 in fetuses from MMI-treated dams were always very low at all times studied, and support the conclusion that the 5'D-II response was caused by thyroid hormone deficiency of the fetal brain.

$\mathrm{T} 4$ concentrations in 17 -day-old fetuses are very low $(0.2 \mathrm{nM})$. This fact raises the question about a different set-point for the regulation of the enzyme during these early stages of brain development.

Effect of maternal thyroid hormones. The adequacy of the dose of T4 used to infuse the pregnant dams, has been extensively discussed in our previous report $(26,33)$. Infusion of $T 4$ into the MMI-treated mothers increased the concentration of T4 and T3 in the fetal brain, mitigating the effects of MMI. The infusion of $\mathrm{T} 3$ to the mother increased fetal plasma $\mathrm{T} 3$, and the $\mathrm{T} 3$ concentration in many fetal tissues (33), but did not mitigate the cerebral T3 deficiency caused by treatment with MMI. It is shown here that $5^{\prime} \mathrm{D}$-II activities clearly responded to the different $\mathrm{T} 4$ concentrations in the fetal brain.

Despite the small amount of T4 transferred to the fetus (at least as is reflected in brain T4 concentrations), it is enough to inhibit 5'D-II in the fetal brain, and to produce a clear increase in brain T3, whereas treatment of the mother with $\mathrm{T} 3$ actually increased brain 5'D-II activity, possibly as a consequence of the further decrease in cerebral T4 level. Despite these increases in 5'D-II activity in MMI and MMI + T3 treated groups, the high activities were unable to maintain brain $\mathrm{T} 3$ concentrations within the normal range (Figs. 5 and 6), possibly due to the lack of substrate: $T 4$.

The inverse relationships found between $5^{\prime} \mathrm{D}-\mathrm{II}$ activities and brain thyroid hormones show that the fetal brain from $\mathrm{T}$ dams is better prepared to respond to a situation of fetal hypothyroidism, as the set-point at which $5^{\prime} \mathrm{D}$-II starts to respond to T4 deficiency is more sensitive in the fetus from $T$ dams. It could be argued that the different responses could be caused by differences in T4 inner-ring deiodinative pathways (5-D) between the fetal brain from $C$ and $T$ dams. In fact, it has been reported that the amount of fetal plasma rT3 is reduced under the situation of maternal thyroidectomy (40), but, unfortunately, brain rT3 production was not studied in this situation, and it is known that the inhibition of brain 5'D-II, if any, is accounted for by rT3 locally produced from T4 (22). There is also evidence that, in the adult brain, rT3 production is lower in hypothyroid than in $C$ rats $(22,41)$. In summary, it is possible that the amount of rT3, as a product of T4 metabolism, is changed in the fetal brain under the situation of maternal thyroidectomy. However, the differences between the curves obtained for $\mathrm{C}$ and $\mathrm{T}$ rats (Fig. 6) do not result from the differences in $5^{\prime} \mathrm{D}$-II activities, but from the higher concentrations of $\mathrm{T} 4$ in the brain from TMMI and TMMI + T4 fetuses, as compared to their respective C groups. This suggests that maternal thyroidectomy, combined with fetal hypothyroidism might increase T4 uptake by the brain, or decrease T4 degradation or exit time. However, neither the possible changes in cerebral rT3 levels nor in T4 concentrations would totally explain the different set-point of the $5^{\prime} \mathrm{D}$-II response to cerebral $\mathrm{T} 4$ concentrations between fetuses from $\mathrm{C}$ and $\mathrm{T}$ dams. The mechanisms that could induce a different sensitivity in the fetal brain from $\mathrm{T}$ dams remain to be elucidated.

In summary, present results report for the first time the ontogenic development of $\mathrm{T} 45^{\prime} \mathrm{D}$-II in the rat fetal brain. During this period, $5^{\prime} \mathrm{D}-\mathrm{II}$ and cerebral concentrations of T4 and T3 are rapidly increasing. The present study also demonstrates that in the rat fetal brain, T3 is derived entirely from $\mathrm{T} 4$ by local deiodination, and at the end of gestation reaches values near the adult thyroid hormone concentrations, despite very low plasma T3 levels. Although during fetal development 5'D-II and thyroid hormone concentrations are all increasing, $5^{\prime} \mathrm{D}$-II is able to respond to cerebral thyroid hormone deficiency. It does so as early in gestation as 17 to $18 \mathrm{dg}$. These results suggest a role for thyroid hormones in fetal brain development, considering that mechanisms are already present to preserve cerebral T3 concentrations. Such a role, however, remains to be defined. 
Acknowledgments. The authors thank Ms. S. Duran, M. J. Presas, and C. Montiel for invaluable technical assistance in the hormonal determinations and tissue extractions, as well as A. Seguido for technical work and the animal care-taker Mr. P. Señor for careful recordings of rat matings.

\section{REFERENCES}

1. Eayrs JT 1960 Developmental relationships between brain and thyroid. In: Michael RP (ed) Endocrinology and Human Behaviour. Oxford University Press, London, pp 239-255

2. Ford DH, Cramer E 1977 Developing nervous system in relation to thyroid hormones. In: Grave GD (ed) Thyroid Hormones and Brain Development. Raven Press, New York, pp 1-18

3. Morreale de Escobar G, Escobar del Rey F, Ruiz-Marcos A 1983 Thyroid hormone and the developing brain. In: Dussault JH, Walker P (eds) Congenital Hypothyroidism. Marcel Dekker, Inc. New York, pp 85-125

4. Balazs R, Brooksbank BWL, Davidson AN, Eayrs JT, Wilson DA 1969 The effect of neonatal thyroidectomy on myelination in the rat brain. Brain Res 15:219-232

5. Pharoah POD, Buttfield IH, Hetzel BS 1971 Neurological damage to the foetus resulting from severe iodine deficiency during pregnancy. Lancet 1:308-310

6. Hetzel BS, Smith RM 1981 Fetal Brain Disorders. Recent Approaches to the Problem of Mental Deficiency. Elsevier/North Holland, Biomedical Press, Amsterdam

7. Legrand J 1986 Thyroid hormone effects on growth and development. IN: Hennemann G (ed) Thyroid Hormone Metabolism. Marcel Dekker, Inc. New York, pp 503-534

8. Francon J, Fellous A, Lennon AM, Nunez J 1977 Is thyroxine a regulatory signal for neurotubule assembly during brain development? Nature 266:188190

9. Schwartz HL, Oppenheimer JH 1978 Nuclear triiodothyronine receptor sites in brain: probable identity with hepatic receptors and regional distribution. Endocrinology 103:267-273

10. Valcana T, Timiras PS 1978 Nuclear triidothyronine receptors in developing rat brain. Mol Cell Endocrinol 11:31-41

11. Haidar MA, Dube S, Sarkar PK 1983 Thyroid hormone receptors of developing chick brain are predominantly in the neurons. Biochem Biophys Res Commun 112:221-227

12. Perez-Castillo A, Bernal J, Ferreiro B, Pans T 1985 The early ontogenesis of thyroid receptor in the rat fetus. Endocrinology 117:2457-2461

13. Obregón MJ, Roelfsema F, Morreale de Escobar G, Escobar del Rey F, Querido A 1979 Exchange of triiodothyronine derived from thyroxine with circulating triiodothyronine as studied in the rat. Clin Endocrinol 10:305-315

14. Crantz FR, Larsen PR 1980 Rapid thyroxine to 3,5,3'-triiodothyronine conversion and nuclear $3,5,3^{\prime}$-triiodothyronine binding in rat cerebral cortex and cerebellum. J Clin Invest 65:935-938

15. van Doorn J, Roelfsema F 1983 Sources and quantity of 3,5,3'-triiodothyronine in several tissues of the rat. J Clin Invest 72:1778-1792

16. Visser TJ, Leonard JL, Kaplan MM, Larsen PR 1981 Different pathways of iodothyronine $5^{\prime}$-deiodination in rat cerebral cortex. Biochem Biophys Res Commun 101:1297-1304

17. Visser TJ, Leonard JL, Kaplan MM, Larsen PR 1982 Kinetic evidence sug gesting two mechanisms for iododthyronine $5^{\prime}$-deiodination rat cerebral cortex. Proc Natl Acad Sci USA 79:5080-5084

18. Leonard JL, Kaplan MM, Visser TJ, Silva JE, Larsen PR 1981 Cerebral cortex responds rapidly to thyroid hormones. Science 214:571-573

19. Kaplan MM, Yaskoski KA 1982 Effects of congenital hypothyroidism and partial and complete food deprivation on phenolic and tyrosyl ring iodothyronine deiodination in rat brain. Endocrinology 110:761-767

20. Leonard JL, Silva JE, Kaplan MM, Mellen SA, Visser TJ, Larsen PR 1984
Acute posttranscriptional regulation of cerebrocortical and pituitary iodothyronine 5'-deiodinases by thyroid hormone. Endocrinology 114:998-1004

21. Silva JE, Leonard JL 1985 Regulation of rat cerebrocortical and adenohypophyseal type II $5^{\prime}$-deiodinase by thyroxine, triiodothyronine, and reverse triiodothyronine. Endocrinology 116:1627-1635

22. Obregon MJ, Larsen PR, Silva JE 1986 The role of 3,3',5'-triiodothyronine in the regulation of type II iodothyronine $5^{\prime}$-deiodinase in the rat cerebral cortex. Endocrinology 119:2186-2192

23. Silva JE, Mathews P 1984 Production rate and turnover of triiodothyronine in rat-developing cerebral cortex and cerebellum: responses to hypothyroidism. $\mathrm{J}$ Clin Invest 74:1035-1049

24. Silva JE Leonard JL, Crantz FR, Larsen PR 1982 Evidence for two tissue specific pathways for in vivo thyroxine $5^{\prime}$-deiodination in the rat. $J$ Clin Invest 69:1176-1184

25. Morreale de Escobar G, Pastor R, Obregón MJ, Escobar del Rey F 1985 Effects of maternal hypothyroidism on the weight and thyroid hormone content of rat embryonic tissues, before and after onset of fetal thyroid function. Endocrinology 117:1890-1900

26. Morreale de Escobar G, Obregón MJ, Ruiz de Oña C, Escobar del Rey F 1988 Transfer of thyroxine from the mother to the rat fetus near term: effects on brain 3,5,3'-triiodothyronine deficiency. Endocrinology 122:1521-1531

27. Weeke J, Orskov H 1973 Synthesis of monolabeled 3,5,3'-triiodo thyronine and thyroxine of maximum specific activity for radioimmunoassay. Scand $\mathrm{J}$ Clin Lab Invest 32:357-360

28. Bellabarba D, Peterson RE, Sterling K 1968 An improved method for chromatography of iodothyronine. J Clin Endocrinol Metab 28:305-307

29. Leonard JL, Rosenberg IN 1980 Iodothyronine 5'-deiodinase from rat kidney: substrate specificity and the $5^{\prime}$-deiodination of reverse triiodothyronine. Endocrinology 107:1376-1383

30. Lowry OH, Rosebrough NJ, Farr AL, Randall RJ 1951 Protein measurement with the Folin phenol reagent. J Biol Chem 193:265-275

31. Obregón MJ, Morreale de Escobar G, Escobar del Rey F 1978 Concentrations of triiodo-L-thyronine in the plasma and tissues of normal rats as determined by radioimmunoassay: comparison with results obtained by an isotopic equilibrium technique. Endocrinology 103:2145-2153

32. Snedecor GV, Cochran WG 1980 Statistical Methods. Iowa State University Press, Ames

33. Morreale de Escobar G, Obregón MJ, Ruiz de Oña C, Escobar del Rey F 1988 Comparison of maternal to fetal transfer of 3,5,3'-triiodothyronine versus thyroxine in rats, as assessed from 3,5,3'-triiodothyronine levels in fetal tissues. Acta Endocrinol (in press)

34. McCann UD, Shaw EA, Kaplan MM 1984 Iodothyronine deiodination reaction types in several rat tissues: effects of age, thyroid status, and glucocorticoid treatment. Endocrinology 114:1513-1521

35. Kaplan MM, Yaskoski KA 1981 Maturational patterns of iodothyronine phenolic and tyrosyl ring deiodinase activities in rat cerebrum, cerebellum and hypothalamus. J Clin Invest 67:1208-1214

36. Tanaka K, Inada M, Ishii H, Naito K, Nishikawa M, Mashio Y, Imura H 1981 Inner ring monodeiodination of thyroxine and 3,5,3'-L-triiodothyronine in rat brain. Endocrinology 109:1619-1624

37. Tanaka $K$, Inada $M$, Mashio $Y$, Ishii $H$, Naito $K$, Nishikawa $M$, Takahashi $K$, Imura H 1982 Characteristics of rT3 5'-monodeiodination in rat brain: comparison with T4 and T3 5 monodeiodinations. Acta Endocrinol 101:371-376

38. Leonard JL, Larsen PR 1985 Thyroid hormone metabolism in primary cultures of fetal rat bran cells. Brain Res 327:1-13

39. Cavalieri RR, Gavin LA, Cole R, de Vellis J 1986 Thyroid hormone deiodinases in purified primary glial cell cultures. Brain Res 364:382-385

40. El-Zaheri MM, Vagenakis AG, Hinerfeld L, Emerson $\mathrm{CH}$, Braverman LE 1981 Maternal thyroid function is the major determinant of amniotic fluid 3,3',5'-triiodothyronine in the rat. J Clin Invest 67:1126-1133

41. Kaplan MM, Yaskoski KA 1980 Phenolic and tyrosyl ring deiodination of iodothyronines in rat brain homogenates. J Clin Invest 66:551-562 